\title{
1 Forest Ecology and Management
}

2

3 Emerald ash borer biocontrol in ash saplings: the potential for early stage recovery of

$4 \quad$ North American ash trees

5

6

$7 \quad$ Jian J. Duan ${ }^{1 *}$, Leah S. Bauer ${ }^{2}$, and Roy G. Van Driesche ${ }^{3}$

8

$9 \quad{ }^{1}$ USDA ARS, Beneficial Insects Introduction Research Unit, Newark, DE 19713

$10 \quad{ }^{2}$ USDA Forest Service, Northern Research Station, Lansing, MI 48910

$11{ }^{3}$ Department of Environmental Conservation, University of Massachusetts, Amherst, MA 01003

12

13 *Corresponding author: jian.duan@ars.usda.gov

14

15

(C) 2017. This manuscript version is made available under the Elsevier user license 
ABSTRACT: In many parts of North America, ash (Fraxinus) stands have been reduced by the emerald ash borer (Agrilus planipennis) invasion to a few surviving mature trees, saplings, basal sprouts, and seedlings. Without a soil seed bank for Fraxinus spp., tree recovery will require survival and maturation of these younger cohorts to reproductive age. Here we report and analyze the population dynamics of emerald ash borer and its associated natural enemies in ash saplings $(2.5-5.8 \mathrm{~cm} \mathrm{DBH})$ in six deciduous forest stands in southern Michigan. At these sites, the outbreak population of the pest collapsed during the study, and a biocontrol agent introduced from China, the larval parasitoid Tetrastichus planipennisi, became widely established and increased in rates of parasitism. To assess the potential for ash recovery in these stands, we also quantified the abundance and crown condition of the ash saplings and surviving ash trees at the study sites. We found that $T$. planipennisi was the dominant biotic mortality factor in saplings,

27 killing 36-85\% of the late instar borer larvae. Neither woodpecker predation nor native parasitoids caused more than minor levels $(<20 \%)$ of borer mortality in saplings. Life table analyses of these data further showed that the net population growth rate of the pest in saplings was near or under replacement levels, and that the introduced biocontrol agent reduced the pest's net population growth rate in saplings at our study sites by over $50 \%$. In addition, stand inventories found that healthy ash saplings (4-16 per $\left.100 \mathrm{~m}^{2}\right)$ and smaller (pole size) trees (2-9

34 the sites. These findings indicate that the introduced biocontrol agent $T$. planipennisi is providing 35 significant biocontrol services, enhancing ash survival and promoting recovery of the ash in 36 southern Michigan. borer. 


\section{Introduction}

North American forests are frequently invaded by non-native insects due to increasing

41 global travel of people and expanding international trade (Liebhold et al., 1995; Brockerhoff et

42 al., 2006; Aukema et al., 2010, 2011). Some of these invasive insects severely damage North

43 American forest ecosystems (Aukema et al., 2010, 2011; Van Driesche and Reardon, 2014). An

44 understanding of the population dynamics of such invasive forest pests is needed when

45 restoration efforts are initiated after the invasion (Lockwood et al., 2007).

The emerald ash borer, Agrilus planipennis Fairmaire, a buprestid beetle native to

47 northeastern Asia, was discovered in North America as the cause of widespread ash tree

48 (Fraxinus spp.) mortality in southeast Michigan and nearby Ontario in 2002 (Haack et al. 2002;

49 Cappaert et al., 2005; Poland and McCullough, 2006). Since then, this invasive beetle has spread

50 throughout much of the eastern United States and Canada, where it has killed hundreds of

51 millions of ash trees (Emerald Ash Borer Information, 2017). In Michigan and Ohio, near the

52 epicenter of the invasion, researchers found $99 \%$ mortality of healthy overstory ash trees within

53 six years of detection of emerald ash borer (Smith 2006; Knight et al., 2013; Klooster et al.,

54 2014). The ecological impacts of such a rapid reduction in ash abundance include changes in

55 forest succession, species composition, and hydrologic processes (Flower et al., 2013; Slesak et

56 al., 2014; Nisbet et al., 2015), losses in biodiversity of ash-dependent species (Gandhi et al.,

57 2014; Wagner and Todd, 2016; Jennings et al., 2016a), and alterations in nutrient and carbon

58 cycles (Ulyshen et al., 2011, 2012; Stephens et al., 2013; Flower et al., 2014).

59 Despite predictions that Fraxinus could be functionally extirpated from North American

60 forests (Herms and McCullough 2014), research shows that tree mortality is moderated by

61 several factors including ash species and genotype (Liu et al., 2003; Rebek et al., 2008; Koch et 
62 al., 2015); ash tree age, vigor, and stand density (Siegert et al., 2010; Kashian and Witter 2011;

63 Mercader et al., 2011; Knight et al., 2013; Kashian 2016); pest population outbreak stages (Burr

64 and McCullough 2014); climatic factors (Wu et al., 2007; Crosthwaite et al., 2011; DeSantis et

65 al., 2013); and natural enemies (Liu et al., 2003, 2007; Lindell et al., 2008; Duan et al., 2010,

66 2012a, 2013a, 2015; Bauer et al., 2015; Jennings et al., 2016b, 2016c; Murphy 2017). Moreover,

67 a recent five-year study of green ash $(F$. pennsylvanica) regeneration in the aftermath forests of

68 southeast Michigan revealed seed production in small ash trees and basal ash sprouts in 2011 and

69 subsequent seedling recruitment throughout the region (Kashian, 2016). These findings suggest

70 that green ash will likely persist in the presence of emerald ash borer and may remain an

71 important forest species, although its stature and population densities may be greatly diminished

72 on the landscape (Kashian, 2016).

73 The natural enemy release hypothesis states that some non-native species achieve pest status

74 because they are accidentally separated from their specialized natural enemies when they arrive

75 to new locations and local species are unable to suppress them (e.g., Keane and Crawley, 2002;

76 Mitchell and Power, 2004; Murphy et al., 2014). Although this hypothesis has been criticized for

77 lack of direct experimental evidence in some cases (e.g., Berdegue et al., 1996; Colautti et al.,

78 2004), many dramatic successes in biological control have resulted from the re-association of

79 such invasive pests with their co-evolved natural enemies from the pests' native ranges (e.g.,

80 Embree, 1966; see case reviews in Clausen, 1978; van den Bosch, et al., 1982; Van Driesche et

81 al., 2010; Van Driesche and Reardon, 2014).

82 Biological control of emerald ash borer was initiated by the United States Department of

83 Agriculture (USDA) shortly after the beetle was detected in North America (Bauer et al., 2008,

84 2015). Following regulatory review and approval, USDA issued permits in 2007 for the 
85

86

87

88

89

90

91

92

93

94

95

96

97

98

99

100

101

102

103

104

105

106

107

environmental release of three emerald ash borer parasitoids from northeast China into the United States: the solitary egg parasitoid Oobius agrili Zhang \& Huang (Hymenoptera: Encyrtidae) and the two gregarious larval parasitoids Tetrastichus planipennisi Yang (Hymenoptera: Eulophidae) and Spathius agrili Yang (Hymenoptera: Braconidae) (Federal Register, 2007). Tetrastichus planipennisi is an endoparasitoid attacking older emerald ash borer larvae (third and fourth instars) (Liu et al., 2003, 2007; Ulyshen et al., 2010), while S. agrili is an ectoparasitoid of the same stages (Yang et al., 2005). Another larval ectoparasitoid, Spathius galinae Belokobylskij \& Strazanac (Braconidae), from the Russian Far East, was approved for release in 2015 in the U.S. (Belokobylskij et al., 2012; Duan et al., 2012b; Federal Register, 2015). Release of T. planipennisi and $O$. agrili continues in emerald ash borer-infested regions of the United States (to date, in 26 of the 31 infested states) and Canada (two provinces). These two species have been consistently recovered more than one year after their release and are considered established in northern regions (Duan et al., 2013a; Abell et al., 2014; Bauer et al., 2015; Mapbiocontrol, 2017). Release of S. agrili, however, is now limited to regions south of the $40^{\text {th }}$ parallel due to lack of establishment in northern regions, while $S$. galinae has been approved since 2015 for release in regions north of the $40^{\text {th }}$ parallel (USDA-APHIS/ARS/FS, 2016).

Since the start of biocontrol releases in 2007, field studies in different regions of North America have monitored emerald ash borer parasitoid populations for their establishment and prevalence (Duan et al., 2013a, 2014, 2015; Abell et al., 2014; 2016; Bauer et al., 2015;

Davidson and Rieske 2016; Parisio et al., 2017; Mapbiocontrol.org 2017). As the pest infestation continues to expand in ash stands in North America, predation of emerald ash borer larvae and pupae by woodpeckers and other bark-foraging birds, and larval parasitism by native 
108

109

110

111

112

113

114

115

116

117

118

119

120

121

122

123

124

125

126

127

128

129

130

parasitoids via new species associations, are regularly observed both in the invasion's epicenter in Michigan (Lindell et al. 2008; Cappaert and McCullough, 2009; Duan et al., 2010, 2014;

Jennings et al., 2016c) and at its expanding edges (e.g., Colorado, Texas, New England, Ontario, and Quebec) (Kula et al., 2010; Duan et al., 2013b; Jennings et al., 2013, 2016b, 2016c; Flower et al., 2014; Roscoe et al., 2016).

A seven-year field study (2008 to 2014) in southern Michigan, following release of the three Chinese parasitoids, showed that parasitism by T. planipennisi and O. agrili contributed significantly to the reduction of net population growth rate $\left(\mathrm{R}_{0}\right)$ of emerald ash borers infesting small to medium ash trees (averaging $8.7-12.1 \mathrm{~cm}$ diameter at breast height [DBH]) four years after their initial release (Duan et al., 2013a, 2015; Abell et al., 2014). These biocontrol agents, together with woodpeckers and native parasitoids, primarily Atanycolus spp., caused target pest densities in infested ash to decline $\sim 90 \%$ (Duan et al., 2015). However, studies are lacking on the impact of introduced and native natural enemies on emerald ash borers attacking ash saplings. Saplings are a critical bridge cohort, whose survival is essential as new ash trees develop from understory seedlings, after the loss of overstory trees (Kashian, 2016).

Here we report results of a three-year study (2013 to 2015) on the impact of natural enemies on emerald ash borer population dynamics in saplings $(2.5-5.8 \mathrm{~cm} \mathrm{DBH})$ at six deciduous forest stands in southern Michigan, where $O$. agrili, T. planipennisi, and S. agrili were released from 2007 to 2010 and where O. agrili and T. planipennisi became widely established (Duan et al., 2010, 2013a; Abell et al., 2014). For emerald ash borer life stages found in ash saplings, we constructed lifetables and estimated population growth rates using methods previously applied in larger ash trees at the same sites from 2008 to 2014 (Duan et al., 2014, 2015). Lifetables for the emerald ash borer in saplings allowed estimation of pest population growth rates with and 
131 without larval parasitism and the contribution to pest reduction due to $T$. planipennisi. To

132 provide insights into the potential future survival and recovery of ash in North American forests,

133 we also assessed ash abundance and crown condition for four size-class ash trees at our study

134 sites.

\section{Methods}

\subsection{Site description}

Our study on saplings was conducted in six forested sites in three southern Michigan

to $60 \mathrm{~km}$ between sites. These sites were primarily early successional, second-growth northern

142 deciduous forests dominated by green ( $F$. pennsylvanica Marsh) and white ash ( $F$. americana

143 L.). Less abundant trees species in these forests were black ash (F. nigra Marsh), red maple

144 (Acer rubrum L.), boxelder (A. negundo L.), oaks (Quercus spp.), black cherry (Prunus serotina

145 Ehrh.), aspen (Populus tremuloides Michx), eastern cottonwood (Populus deltoides Bartr. ex

146 Marsh), black walnut (Juglans nigra L.), American basswood (Tilia america L.), and some pine

147 (Pinus) species. The location of these sites is described in Duan et al. (2013a).

\subsection{Biological control agents released}


153 location. From 2007 to 2010, O. agrili, S. agrili, and T. planipennisi were introduced into each

154 release plot. Detailed information on release procedure, timing, frequency, and number of adult 155 wasps released for each species can be found in Duan et al. (2015).

156

157

2.3. Sampling procedures for the pest and its natural enemies

158

159

We haphazardly selected 10 ash saplings $(2.5-5.8 \mathrm{~cm} \mathrm{DBH})$ at each of the six release and

160 six control plots at various points from January through April in 2014, 2015, and 2016 (120

161 saplings/year). Saplings were measured for DBH, felled, labeled in the field, and then returned to

162 the laboratory, stored in buckets of water in a walk-in cold room $\left(4^{\circ} \mathrm{C}\right)$ until each was carefully

163 debarked on a shaving bench (Country Workshops, Marshall, NC) with an Austrian drawknife

164 (Lee Valley Tools Ltd., Ogdensburg, NY) for detection of emerald ash borer feeding galleries

165 and recovery of live stages of the pest and associated parasitoids. The observed insects hatched

166 from eggs laid the previous year. In addition to measuring larval parasitism rates in the saplings,

167 we also determined mortality rates associated with other factors, including avian predation

168 (primarily from woodpeckers) and undermined biotic factors such as putative host tree

169 resistance, intraspecific competition, and/or disease.

170 Procedures for determining the pest's larval instar and the species of associated parasitoids

171 or recognition of other mortality factors upon debarking of the saplings are described in Duan et

172 al. (2015). Briefly, each emerald ash borer gallery or pupation chamber (formed by mature $4^{\text {th }}$ -

173 instar larvae) was examined upon removal of both outer and inner bark tissues on the stems of

174 saplings. For all current galleries, emerald ash borer larval stages were classified as small $\left(1^{\text {st }}\right.$ to

$1752^{\text {nd }}$ instars, with gallery widths $\left.\leq 2 \mathrm{~mm}\right)$ or large $\left(3^{\text {rd }}\right.$ to $4^{\text {th }}$ instars, including J-shaped, mature 
176 larvae, with gallery widths $>2 \mathrm{~mm}$ ). Each larva was assigned to one of five categories, as

177 described in Duan et al. (2015): (1) insects that had completed their development, evidenced as

178 D-shaped adult emergence holes, (2) live larvae, (3) larvae or pupae removed by avian predators

179 as evidenced by excavation above empty pest galleries or pupation chambers, (4) cadavers of

180 larvae or pupae dead due to undetermined factors (e.g., host tree defenses, pathogens,

181 intraspecific larval competition, or weather), and (5) parasitized larvae, as indicated by the

182 presence of parasitoid eggs, larvae, pupae, cocoons, pharate adults, meconium, or exit holes

183 associated with live or dead host galleries.

Because the signs and symptoms of parasitism may not be always visible externally, each

185 live emerald ash borer larva that did not show any obvious signs of parasitism was dissected

186 under a dissecting stereomicroscope to look for immature parasitoid stages or their remains.

187 Parasitoids could be identified to species in the case of the gregarious endoparasitic biocontrol

188 agent T. planipennisi or to genus for the dominant native solitary ectoparasitoids, Atanycolus

189 spp., according to procedures described in Duan et al. (2013a).

\subsection{Ash abundance and health conditions}

192

In the summer (mid-July to early August) of 2015, eight belt transects (four in each

194 biocontrol-release plot and four in each non-release control plot, at each of the six sites) were

195 haphazardly established inside study plots using Hip Chain Distance Measurers (Forestry

196 Supplier Inc., Jackson, Mississippi). Each transect was 50-m long and 2-m wide (100 $\mathrm{m}^{2}$ of

197 area), with transects being at the minimum of $10 \mathrm{~m}$ and the maximum of $500 \mathrm{~m}$ from each other

198 within each study plot. All ash (saplings or trees with $\mathrm{DBH}>1 \mathrm{~cm}$ ) inside each transect area were 
recorded and examined for any signs of EAB infestation (including D-shaped exit holes, epicormic growth, and signs of current-year woodpecker feeding). The crown condition of each sapling and tree was assessed using the crown decline and dieback scale of 1 to 5 developed by Smith (2006) and modified with 0.5 increments. Briefly, a score of 1.0 represented an ash with a healthy crown, and scores that ranged from 1.5 to 4.5 indicated increasing crown decline, with the highest score of 5.0 representing a dead crown.

\subsection{Data analysis}

A mixed-effects linear model for Analysis of Variance (ANOVA), as described in Duan et al. (2015), was used to evaluate differences in the resource-adjusted pest density (number of live emerald ash borer larvae or pupae per $\mathrm{m}^{2}$ of phloem area of sampled saplings) between parasitoid-release and non-release control plots. The total phloem area $(y)$ of each sapling was estimated using a second-order polynomial model $\left(y=0.024 x^{2}-0.307 x+2.63\right)$ as a function of sampling DBH (x) (McCullough and Siegert, 2007). Log likelihood Chi-square tests (based on a nominal logistic regression model of binomial distribution data) were used to evaluate differences in larval mortality rates caused by different parasitoids, avian predators as a group, and undetermined factors. Mortality rates caused by larval parasitoids were calculated as marginal attack rates by excluding from the denominator any pest larvae killed by avian predators or undetermined factors. This calculation of marginal attack rate was based on the assumption that avian predators and agents in the "undetermined factor" category acted on pest larvae contemporaneously with the larval parasitoids and showed no discrimination between healthy and parasitized emerald ash borer larvae (Elkinton et al., 1992; Duan et al., 2015). However, mortality rates from avian predators and undetermined factors were calculated as the 
222 proportion of individuals dying from each of these causes relative to the total number of

223 individuals (dead and live) in all emerald ash borer life stages because these biotic factors

224 occurred at all pest stages, regardless of their condition or previous attack by other factors. All

225 statistical analyses were carried out with JMP Pro 12.01 (SAS Institute 2014), and the outputs,

226 along with statistical program scripts, are presented in Appendix A (Supplementary

227 Information).

228 Life table construction procedures as described by Duan et al. (2015) were used to 229 construct life tables for pest populations. These tables were based on the observed number of live 230 or dead pest larvae or pupae found each year at the site, by pooling data from the release and 231 control plots at each site. However, unlike in Duan et al. (2015), no additional overwintering 232 mortality was added to calculate the net population growth rate $\left(\mathrm{R}_{0}\right)$ in the present study because 233 saplings were sampled from winter through early spring, not in the fall as in Duan et al. (2015).

234 We estimated the number of emerald ash borer eggs for the beginning of the following $\left(\mathrm{F}_{1}\right)$ 235 generation from the number of surviving immature stages $\left(3^{\text {rd }}\right.$ and $4^{\text {th }}$ instars $)$, applying a sex 236 ratio of 0.5 to estimate the number of females, and an average of 30 viable eggs per gravid 237 female, as per Rutledge and Keena (2012). The mixed-effects ANOVA model was used to detect 238 the statistical significance of the effect of parasitism, by either $T$. planipennisi alone or in 239 combination with the native parasitoids (Atanycolus spp.) on pest population growth rates. 
Throughout the three-year study, 20-35\% of sampled saplings had signs of current emerald

245

246

247

248

249

250

251

252

253

254

255

256

257

258

259

260

261

262

263

264

265

266

57

58

ash borer infestation in both the biocontrol release and non-release control plots at the six study sites (Fig. 1A). When adjusted to the area of ash phloem $\left(\right.$ per $\left.\mathrm{m}^{2}\right)$, the mean number of live pest larvae (all instars) in the infested saplings was $2-7$ per $\mathrm{m}^{2}$ in both release and control plots during the study period (Fig. 1B). There was no significant difference in the pest infestation rate between saplings in the release and control plots (logistic regression model: log likelihood $\chi^{2}=$ $0.5857, P=0.7641)$, nor were there any significant differences in the mean pest density between the release and control plots (mixed linear ANOVA, $F_{1,73}=0.3792 ; P=0.5399$ ). However, logistic regression analysis revealed significant differences in sapling infestation rates by the pest among different sampling years (log likelihood $\left.\chi^{2}=9.73, P=0.0452\right)$ as well as among different study sites $\left(\log\right.$ likelihood $\left.\chi^{2}=25.83 ; P=0.0040\right)$.

\subsection{Mortality of emerald ash borer larvae from different groups of natural enemies}

Two parasitoid groups were observed attacking late-instar pest larvae $\left(3^{\text {rd }}\right.$ and $4^{\text {th }}$ instar) infesting saplings in both release and non-release plots at the six study sites throughout the threeyear study period: the introduced biological control agent $T$. planipennisi and native species of Atanycolus. Tetrastichus planipennisi was the dominant parasitoid (>92\% of all cases of larval parasitism), attacking 36-85\% of late-instar larvae (Fig. 2A). In contrast, parasitism rate by Atanycolus spp. was 1-20\% (Fig. 2B) during the study period. There were no significant differences in T. planipennisi parasitism between release and control plots (log likelihood $\chi^{2}=$ $3.28, P=0.0694)$, nor in parasitism rates by Atanycolus spp. between release and control plots ( $\log$ likelihood $\left.\chi^{2}<0.0001 ; P=0.9984\right)$. There were no significant interaction effects on 
267 parasitism rates by either T. planipennisi or Atanycolus spp. between biocontrol treatments

268 (release vs control) and the sampling year (all $P>0.10$ ).

269 Avian predation of immature pest life stages was $<10 \%$ throughout the study period in both

270 release and control plots (Fig. 3A). Larval mortality of pests from undetermined factors (e.g.,

271 putative plant resistance, pathogens, intraspecific larval competition, and weather) was $2-23 \%$

272 (Fig. 3B) in both release and control plots. There were no significant differences in the rates of

273 avian predation between the release and control plots, nor were there any significant interactions

274 between biocontrol treatments and sampling year (all $P>0.10$ ). However, the pest mortality rate

275 caused by the undetermined factors was significantly higher in release plots than in control plots

276 in $2014\left(\log\right.$ likelihood $\left.\chi^{2}=7.61 ; P=0.0058\right)$.

277

278

3.3. Effect of introduced biocontrol agents on pest net population growth rate

279

280

281

282

283

284

285

286

287

288

289
A representative life table, based on the immature stages of emerald ash borer at Rose Lake State Wildlife Area (combining the release and control plot data) for 2015, shows rates of apparent (stage-specific) mortality and associated mortality factors, real mortality, and estimates of pest net population growth rate $\left(\mathrm{R}_{0}\right)$ (Table 1$)$. The impact of the biocontrol agent $T$.

planipennisi on target pest population growth was assessed by the change in the $\mathrm{R}_{0}$ value when mortality from $T$. planipennisi was removed from the life table, with the assumption that all subsequent mortality factors would kill the same percentage of the pest (i.e., none were density dependent). When parasitism by $T$. planipennisi was removed from this life table, $\mathrm{R}_{0}$ values doubled, increasing from 2.2 to 4.4 (Table 1). This change indicates that larval parasitism by $T$. planipennisi reduced the pest population growth at this site by $50 \%$. 
Data from life tables constructed for one complete generation in each year at each of the six

291

292

293

294

295

296

297

298

299

300

301

302

303

304

305

306

307

308

309

310

311

312

study sites (pooling data from parasitoid-release and control plots) showed that on average $\mathrm{R}_{0}$

values were near one, the threshold of replacement (Fig. 4). When parasitism by T. planipennisi

was removed from the life table, $\mathrm{R}_{0}$ values for the pest populations increased over $100 \%$ in each

of the three study years (Fig. 4 - green dotted line), indicating the importance of this biocontrol agent in suppressing population growth of emerald ash borers in ash saplings. Further life table analyses showed that the native Atanycolus parasitoids had only a minor effect on pest $\mathrm{R}_{0}$ values, especially in 2014 and 2015 (Fig. 5 - red dotted line). ANOVA (Appendix A) revealed significant effects of parasitism by $T$. planipennisi (regardless of the presence of the native parasitoids) on population growth rates of emerald ash borers in all three years of the study (mixed linear model, $F_{2,40}=4.5 ; P=0.0172$ ).

\subsection{Survival of ash saplings and trees in the study sites}

There were no significant differences in either average ash tree size (DBH) or density (number of trees and/or saplings per $100 \mathrm{~m}^{2}$ transect) between release and control plots at the six study sites. Pooled data from release and control plots showed that healthy ash saplings and smaller trees (crown classes of 1 to 2 ) remained abundant in the six study sites. The average density of healthy ash saplings (1-5.8 cm DBH) and small ash trees (5.1-10.1 cm DBH) across different study sites was 4-16 and 2-9 per $100 \mathrm{~m}^{2}$ (= 0.01 ha) transect, respectively (Fig. 5A). However, the density of larger healthy ash trees $(\mathrm{DBH}>20.1 \mathrm{~cm})$ was relatively low $(<1$ tree per $100 \mathrm{~m}^{2}$ transect). The density of declining ash trees (crown classes 2.5 to 3.5 ), as well as dying or dead trees (crown classes 4 to 5), was low and similar across all sites (Fig. 5B and 5C). 
Data pooled from all sites showed that the proportion of healthy ash saplings or trees (with

crown classes of 1 to 2 ) decreased with DBH category (or tree age), from $80 \%$ for the saplings $(1-5 \mathrm{~cm} \mathrm{DBH})$ to $<25 \%$ for the large trees $(>20.1 \mathrm{~cm} \mathrm{DBH})$ (Fig. 6). Nominal logistic regression analysis indicated that the crown class category, as a measure of ash health condition, varied highly significantly among different study sites (Likelihood $\left.\chi^{2}=157.42 ; P<0.0001\right)$ as well as with the DBH of the trees or saplings (Likelihood $\chi^{2}=132.65 ; P<0.0001$ ).

\section{Discussion}

A previous seven-year field study conducted at the same locations showed that local, generalist natural enemies such as woodpeckers and native parasitoids provided significant biological control of emerald ash borers infesting small to medium ash trees (averaging $8-12 \mathrm{~cm}$ DBH) during the outbreak phase of pest invasion (Duan et al., 2015). However, this same study also showed that the biocontrol service of pest suppression gradually shifted to the introduced specialist parasitoid T. planipennisi following the collapse of emerald ash borer populations. Data from the present study showed that the introduced biocontrol agent $T$. planipennisi has also become the dominant biotic factor affecting emerald ash borer larvae attacking ash saplings in aftermath forests affected by the pest invasion. Data on ash densities from 2015, the last year of

the present study, also showed that healthy ash saplings and small trees remained in the six study sites. Findings from this study, together with those from the earlier ones on pest populations infesting small to medium size ash trees (Duan et al., 2013a, 2015), demonstrate that the introduced biocontrol agent $T$. planipennisi has firmly established self-sustaining populations in these locations in Michigan and is suppressing pest population densities in these ash-dominant 
336 forests. The biocontrol of emerald ash borer by T. planipennisi also significantly contributes to

337 the survival of sapling and young ash trees in Michigan and should continue promoting ash 338 recovery.

However, previous studies also showed that $T$. planipennisi primarily parasitizes emerald ash borer larvae in smaller trees or branches rather than boles of larger trees (Liu et al. 2007; Duan et al., 2012b; Jennings et al., 2016b), due to bark thickness, which increases with tree size

342 (Abell et al., 2012; Murphy, 2016). The high parasitism rate (36-85\%) of late-instar larvae in ash saplings $(\mathrm{DBH}<5.8 \mathrm{~cm}$ ) is consistent with this limitation given the better match between the parasitoid's ovipositor length (average 2.0-2.5 mm) and bark thickness in such small trees. Bark thickness is known to prevent parasitoids of this species from attacking host larvae in the lower 346 boles of trees that exceed $12 \mathrm{~cm} \mathrm{DBH}$ (corresponding to a bark thickness of $3.2 \mathrm{~mm}$ ) (Abell et 347 al., 2012). To successfully control emerald ash borer in larger ash trees, however, additional 348 efforts are needed to establish a specialized emerald ash borer larval parasitoid with a longer 349 ovipositor, such as the braconid wasp S. galinae, which was first released at these study sites in 2015. Should $S$. galinae establish, it is likely to be more effective in larger diameter ash trees 351 because of its longer ovipositor (4-6 mm), allowing it to successfully parasitize emerald ash 352 borer larvae in ash trees up to 30-cm DBH (Duan et al. 2012a). In addition, egg parasitoids introduced from emerald ash borer's native range may also 354 help protect all size class ash trees against infestation, as they kill the borers before damage to 355 the tree phloem. However, the current level of egg parasitism by O. agrili $(<29 \%$, see Abell et 356 al., 2014) is insufficient to protect ash trees by itself. Introduction of other egg parasitoids, such 357 as O. primorskyensis Yao \& Duan, may enhance egg parasitism (Larson and Duan, 2016). 358 Recovery of native Fraxinus spp. in forest stands invaded by emerald ash borer in North 
359 America will require protection and survival of ash trees across their life cycle and across many

360 climate zones.

361 Avian predation rates of emerald ash borer larvae or pupae in small to large ash trees

362 (primarily by several species of woodpeckers) are high (20-95\%) in many regions, including

363 Michigan (Lindell et al., 2008; Flower et al., 2014; Jennings et al., 2013, 2016c). However, low-

364 to-moderate mortality rates (6-28\%) of emerald ash borer larvae or pupae by undetermined

365 factors were observed in previous studies conducted at the same locations (Duan et al., 2013a,

366 2015). In contrast, in the present study there was very little avian predation $(<10 \%)$ of emerald

367 ash borer larvae and pupae infesting ash saplings, and low-to-moderate level of mortality rates (2

$368-23 \%$ ) from undermined factors. This discrepancy in pest mortality rates caused by avian

369 predators and undetermined factors between the previous and present studies may be due to

370 lower host densities and to difference in the physical and/or chemical properties between ash

371 saplings and mature trees. For example, avian predators (primary woodpeckers) may not prefer

372 foraging on saplings due to its limited support for bird movement while actively feeding. On the

373 other hand, ash saplings may be less resistant to emerald ash borer larvae than are the larger ash

374 trees.

375 Previous research at the same locations in which we sampled small to medium ash trees, 376 revealed no significant differences in parasitism by Atanycolus between release and control plots

377 (Duan et al. 2015). Additionally, parasitism rates by Atanycolus spp. in pole-sized trees

378 decreased sharply as emerald ash borer densities collapsed in these study sites (Duan et al.,

379 2015). In the present study of ash saplings, we found very low rates of Atanycolus parasitism

380 and no significant differences between release and control plots. Life table analyses from the

381 present study further showed that Atanycolus spp. played a non-significant role in reducing 
382

383

384

385

386

387

388

389

390

391

392

393

394

395

396

397

398

399

400

401

402

403

404

emerald ash borer population growth in saplings. The low level of Atanycolus parasitism observed in the present study may be related to the low density of host larvae in saplings rather than interspecific competition with the introduced biocontrol agent $T$. planipennisi. This is because species of Atanycolus are generalist parasitoids, which attack many groups of woodboring beetles occurring at high densities before discovering emerald ash borer as a novel host in North America (Marsh et al., 2009).

Consistent with results from our previous study of emerald ash borer populations in small to medium ash trees (Duan et al., 2015), no significant differences in T. planipennisi parasitism rate and pest density were found in ash saplings between the release and control plots. This resulted from the spread of $T$. planipennisi from the release plots to the control plots at each study site. Recent studies have shown that adults of $T$. planipennisi can disperse $>1 \mathrm{~km}$ within one field season following release (Duan et al., 2012b, 2013, 2015). As demonstrated in this and previous studies (e.g., Van Driesche and Taub, 1983, Jennings et al. 2013; Duan et al. 2014, 2015), construction of life tables of the targeted pest population and subsequent analysis of net population growth rates with and without the biocontrol agent's effect provides a powerful method to quantify the effect of biological control programs on the pest population dynamics. Unlike the results from our previous study with small to medium ash trees, the mean $\mathrm{R}_{0}$ value of emerald ash borers in ash saplings was near one in the first two years of the study (2013 and 2014) and slightly below one in the last year of the study (2015). These $\mathrm{R}_{0}$ values indicate that emerald ash borer populations infesting ash saplings at the current level of densities (2-7 larvae per $\mathrm{m}^{2}$ of sampled phloem) are near or below replacement levels and insufficient to kill ash saplings during this study. A recent study in urban forests shows that infested ash trees could recover from a density of 10 emerald ash borer larvae per $\mathrm{m}^{2}$ of phloem (MacQuarrie and 
405 Scharbach 2015). Given that the introduced larval parasitoid T. planipennisi, as well as the egg

406 parasitoid $O$. agrili (not analyzed in this study, but see Abell et al., 2014) have established stable

407 populations and provide significant pest biocontrol services, we are hopeful that ash saplings in

408 the aftermath forests of southern Michigan can survive sufficiently to successfully reproduce

409 (Kashian and Witter, 2011). Tree survival rates are expected to decline as saplings and small

410 trees mature unless biocontrol protection can be extended to larger trees through the introduction

411 and establishment of new biocontrol agents. To allow for better recovery of North American ash

412 following the invasion of emerald ash borer, we strongly suggest expanded releases of $S$.

413 galinae, which has a considerably longer ovipositor and may complement T. planipennisi in

414 regulating borer populations attacking larger size class ash trees. Furthermore, as the emerald ash

415 borer expands its range in North America, we encourage more foreign exploration in Asia for

416 natural enemies adapted to different climate zones.

418 Acknowledgments

420 We thank Deborah Miller and Toby Petrice (USDA Forest Service, Northern Research Station), 421 Jonathan Schmude (USDA ARS Beneficial Insects Introduction Research Units), Erin Morris

422 (Michigan State University, Department of Entomology), and many Michigan State University

423 student employees for assisting in laboratory work and field surveys of emerald ash borer larvae

424 and their parasitoids on ash saplings. We are also grateful to Kim Hoelmer (USDA Agricultural

425 Research Service) for helpful comments on an early version of this manuscript, and Richard 
426 Reardon and Steven Katovich (USDA Forest Service, State and Private Forestry) for providing

427 partial financial support for this project.

428

429 Appendix A. Supplementary material

430

431 These data include scripts and outputs of all statistical analyses using JPM Pro 11.02.

432

433 Data Accessibility

434

435 Data reported in this article including lifetable parameter estimates are available through the Ag 436 Data Commons (National Agricultural Library, USDA ARS):

437 http://dx.doi.org/10.15482/USDA.ADC/1347361 (Reserved)

438

439 
441

442

443

444

445

446

447

448

449

450

451

452

453

454

455

456

457

458

459

460

Abell, K.J., Duan, J.J., Bauer, L.S., Lelito, J.P., Van Driesche, R.G., 2012. The effect of bark thickness on host partitioning between Tetrastichus planipennisi (Hymen: Eulophidae) and Atanycolus spp. (Hymen: Braconidae), two parasitoids of emerald ash borer (Coleop: Buprestidae). Biol. Control 63, 320-325. http://dx.doi.org/10.1016/j.biocontrol.2014.08.002

Abell, K.J., Bauer, L.S., Duan, J.J., Van Driesche., R.G., 2014. Long-term monitoring of the introduced emerald ash borer (Coleoptera: Buprestidae) egg parasitoid, Oobius agrili (Hymenoptera: Encyrtidae), in Michigan, USA and evaluation of a newly developed monitoring technique. Biol. Contr. 79, 36-42. http://dx.doi.org/10.1653/024.099.0413

Abell, K.J., Bauer, L.S.; Miller, D.L.; Duan, J.J.; Van Driesche, R.G., 2016. Monitoring the establishment and flight phenology of parasitoids of emerald ash borer (Coleoptera: Buprestidae) in Michigan by using sentinel eggs and larvae. Fl. Entomol. 99, 667-672. http://dx.doi.org/10.1653/024.099.0413

Aukema, J.E., Leung, B., Kovacs, K., Chivers, C., Britton, K.O., Englin, J., Frankel, S.J., Haight, R.G., Holmes, T.P., Liebhold, A.M., Mccullough, D.G., Von Holle, B., 2011. Economic impacts of non-native forest insects in the continental United States. PLoS ONE, 6(9), e24587. doi: 10.1371/journal.pone.0024587

Aukema, J.E., Mccullough, D.G., Von Holle, B., Liebhold, A.M., Britton, K., Frankel, S.J., 2010. Historical accumulation of nonindigenous forest pests in the continental United States. Biosci. 60, 886-897. doi:10.1525/bio.2010.60.11.5. 
Burr, S.J., McCullough, D.G., 2014. Condition of green ash (Fraxinus pennsylvanica) overstory and regeneration at three stages of the emerald ash borer invasion wave. Can. J. For. Res., 44, 768-776.

Bauer, L.S., Liu, H.P., Miller, D.L., Gould, J., 2008. Developing a classical biological control program for Agrilus planipennis (Coleoptera: Buprestidae), an invasive ash pest in North America. Newsl. Michigan Entomol. Soc. 53, 38-39.

Bauer, L.S., Duan, J.J., Gould, J.G., Van Driesche, R.G., 2015. Progress in the classical biological control of Agrilus planipennis Fairmaire (Coleoptera: Buprestidae) in North America. Can. Entomol. 147, 300-317. doi:10.4039/tce.2015.18

Berdegue M., Trumble, J.T., Hare J.D., Redak R.A., 1996. Is it natural enemy free space? The evidence for terrestrial insects and freshwater arthropods. Ecol. Entomol. 21, 203-217.

Belokobylskij, S.A., Yurchenko, G.I., Strazanac, J.Z., Zaldı'var-Rivero’', N.A., Mastro, V., 2012. A new emerald ash borer (Coleoptera: Buprestidae) parasitoid species of Spathius Nees (Hymenoptera: Braconidae: Doryctinae) from the Russian Far East and South Korea. Ann. Entomol. Soc. Am. 105, 165-178. http://dx.doi.org/10.1603/AN11140

Brockerhoff, E.G., Liebhold, A.M., Jactel, H., 2006. The ecology of forest insect invasions and advances in their management. Can. J. For. Res. 36, 263-268. doi:10.1139/X06-013

Cappaert, D., McCullough, D.G., Poland, T.M., Siegert, N.W., 2005. Emerald ash borer in North America: a research and regulatory challenge. Am. Entomol. 51, 152-165.

Cappaert, D., McCullough, D.G., 2009. Occurrence and seasonal abundance of Atanycolus cappaerti (Hymenoptera: Buprestidae), a native parasitoid of emerald ash borer, Agrilus planipennis (Coleoptera: Buprestidae). Great Lakes Entomol. 42, 16-29. 
Clausen, C.P., 1978. Introduced Parasites and Predators of Arthropod Pests and Weeds: a World Review. Agricultural Handbook No. 480. United States Department of Agriculture, Washington, D.C.

Colautti, R.I., Ricciardi, A., Grigorovich, I.A., Maclssac, H.J., 2004. Is invasion success by natural enemy release hypothesis? Ecol. Lett 7, 221-233. doi: 10.1111/j.14610248.2004.00616.x

Crosthwaite, J.C., Sobek, S., Lyons, D.B., Bernards, M.A., Sinclair, B.J., 2011. The overwintering physiology of the emerald ash borer, Agrilus planipennis Fairmaire (Coleoptera: Buprestidae). J. Insect Physiol. 57, 166-173. doi:10.1016/j.jinsphys.2010.11.003

Davidson, W., Rieske. L.K., 2016. Establishment of classical biological control targeting emerald ash borer is facilitated by use of insecticides, with little effect on native arthropod communities. Biol. Contr. 101, 78-86. http://dx.doi.org/10.1016/j.biocontrol.2016.06.010

DeSantis, R.D., Moser, W.K., Gormanson, D.D., Bartlett, M.G., Vermunt, B., 2013. Effects of climate on emerald ash borer mortality and the potential for ash survival in North America. Agri. For. Meteorol. 178-179, 120-128. http://dx.doi.org/10.1016/j.agrformet.2013.04.015

Duan, J.J., Ulyshen, M.D., Bauer, L.S., Gould, J., Van Driesche, R.G., 2010. Measuring the impact of biotic factors on populations of immature emerald ash borer (Coleoptera: Buprestidae). Environ. Entomol. 39, 1513-1522. http://dx.doi.org/10.1603/EN10023

Duan, J.J., Bauer, L.S., Abell, K.J., Van Driesche, R.G., 2012a. Population responses of hymenopteran parasitoids to the emerald ash borer (Coleoptera: Buprestidae) in recently 
invaded areas in north central United States. BioControl 57, 199-209. doi:10.1016/j.biocontrol.2011.11.007

Duan, J.J., Yurchenko, G., Fuester, R.W. 2012b. Occurrence of emerald ash borer (Coleoptera: Buprestidae) and biotic factors affecting its immature stages in the Russian Far East. Environ. Entomol. 41, 245-254. http://dx.doi.org/10.1603/EN11318

Duan J.J., Bauer, L.S., Abell, K.J., Lelito, J.,Van Driesche R.G., 2013. Establishment and abundance of Tetrastichus planipennisi (Hymenoptera: Eulophidae) in Michigan: potential for success in classical biocontrol of the invasive emerald ash borer (Coleoptera: Buprestidae). J. Econ. Entomol. 106, 1145-1154. http://dx.doi.org/10.1603/EC13047

Duan, J. J., Taylor, P.B., Fuester, R.W., Kula, R.R., Marsh, P.M., 2013b. Hymenopteran parasitoids attacking the invasive emerald ash borer (Coleoptera: Buprestidae) in western and central Pennsylvania. Florida Entomol. 96, 166-172. http://dx.doi.org/10.1653/024.096.0122

Duan, J.J., Bauer, L.S., Abell, K.J., Van Driesche, R.G., 2014. Natural enemies implicated in the regulations of an invasive pest: a life table analysis of the population dynamics of the invasive emerald ash borer. Agri. For. Entomol. 16, 406-416. DOI: 10.1111/afe.12070

Duan, J.J., Bauer, L.S., Abell, K.J., Ulyshen, M.D., Van Driesche, R.G., 2015. Population dynamics of an invasive forest insect and associated natural enemies in the aftermath of invasion: implications for biological control. J. Appl. Ecol. 52, 1246-1254. doi: $10.1111 / 1365-2664.12485$

Elkinton, J.S., Buonaccorsi, J.P., Bellows, T.S., Van Driesche, R.G., 1992. Marginal attack rate, $\mathrm{k}$-values and density dependence in the analysis of contemporaneous mortality factors. Popul. Ecol. 34, 29-44. 
Embree, D.G., 1966. The role of introduced parasites in the control of the winter moth in Nova Scotia. Can. Entomol. 98, 1159-68.

Emerald Ash Borer Information. 2017. Emerald Ash Borer Information Network. http://www.emeraldashborer.info/, accessed March 15, 2016

Federal Register, 2007. Availability of an environmental assessment for the proposed release of three parasitoids for the biological control of the emerald ash borer (Agrilus planipennis) in the continental United States. Federal Register 72: 28947-28948 [Docket No. APHIS2007-006]. http://www.regulations.gov/\#!documentDetail;D=APHIS-2007-0060-0043 [accessed 30 December 2016]

Federal Register, 2015. Availability of an environmental assessment for field release of the parasitoid Spathius galinae for the biological control of the emerald ash borer (Agrilus planipennis) in the contiguous United States. Federal Register 80(19), 7827 [Docket No. APHIS-2014-0094]. https://www.regulations.gov/docket?D=APHIS-2014-0094 [accessed 30 December 2016]

Flower, C.E., Knight, K.S., Gonzalez-Meler, M.A., 2013. Impacts of the emerald ash borer (Agrilus planipennis Fairmaire) induced ash (Fraxinus spp.) mortality on forest carbon cycling and successional dynamics in the eastern United States. Biol. Invasions 15, 931944. DOI 10.1007/s10530-012-0341-7

Flower, C.E., Long, L.C., Knight, K.S., Rebbeck, J., Brown J.S., Gonzalez-Meler, M.A., Whelan, C.J., 2014. Native bark-foraging birds preferentially forage in infected ash (Fraxinus spp.) and prove effective predators of the invasive emerald ash borer (Agrilus planipennis Fairmaire). Forest Ecol. and Manag. 313, 300-306. http://dx.doi.org/10.1016/j.foreco.2013.11.030 
552 Gandhi, K.J.K., Smith, A., Hartzler, D.M., Herms, D.A., 2014. Indirect effects of emerald ash 553 borer-induced ash mortality and canopy gap formation on epigaeic beetles. Environ. Entomol. 43, 546-555. DOI 10.1007/s10530-009-9594-1

555 Haack, R.A., Jendek, E., Liu, H.P., Marchant, K.R., Petrice, T.R., Poland, T.M., Ye, H., 2002. 556 The emerald ash borer: a new exotic pest in North America. Newsl. Michigan Entomol.

558 Soc. 47, 1-5.

Herms, D.A., McCullough, D.G., 2014. Emerald ash borer invasion of North America: history, biology, ecology, impact and management. Ann. Rev. Entomol. 59, 13-30. doi: 10.1146/annurev-ento-011613-162051

Jennings, D. E., Gould, J.R, Vandenberg, J.D., Duan, J.J., Shrewsbury, P.M., 2013. Quantifying the impact of woodpecker predation on population dynamics of the emerald ash borer (Agrilus planipennis). PLoS ONE, 8(12), e83491. doi:10.1371/journal.pone.0083491.

Jennings, D.E., Duan, J.J., Bean, D., Rice, K.A., Williams, G. Bell, S., Shurtleff A., Shrewsbury, P.M., 2016a. Effects of the emerald ash borer invasion on the community composition of arthropods associated with ash tree boles in Maryland, USA. Agric. Forest Entomol. DOI: $10.1111 /$ afe.12186

Jennings, D.E., Duan, J.J., Bean, D., Gould, J.R., Rice, K.A., Shrewsbury, P.M., 2016 b. Monitoring the establishment and abundance of introduced parasitoids of emerald ash borer larvae in Maryland, U.S.A. Biol. Contr. 101, 138-144. http://dx.doi.org/10.1016/j.biocontrol.2016.07.006.

Jennings, D.E., Duan, J.J., Bauer, L.S., Wetherington, M.T., Schmude, J.M., Shrewsbury, P.M., 2016c. Temporal dynamics of woodpecker predation on emerald ash borer (Agrilus 
planipennis) in the northeastern U.S.A. Agri. For. Entomol. 18, 174-181. DOI:

575

576

577

578

579

580

581

582

583

584

585

586

587

588

589

590

591

592

593

594

595

596

10.1111/afe.12142

Kashian, D.M. 2016. Sprouting and seed production may promote persistence of green ash in the presence of the emerald ash borer. Ecosphere 7(4): e01332. 10.1002/ecs2.1332

Kashian, D.M., Witter, J.A., 2011. Assessing the potential for ash canopy tree replacement via current regeneration following emerald ash borer-caused mortality on southeastern Michigan landscapes. For. Ecol. and Manag. 261, 480-488.

doi:10.1016/j.foreco.2010.10.033

Keane, R.M., Crawley, M.J., 2002. Exotic plant invasions and the enemy release hypothesis. Trends Ecol. Evol. 17, 164-170.

Knight, K.S., Brown, J.P., Long, R.P., 2013. Factors affecting the survival of ash (Fraxinus spp.) treesinfested by emerald ash borer (Agrilus planipennis). Biol. Invasions 15, 371-383. DOI $10.1007 / \mathrm{s} 10530-012-0292-\mathrm{z}$

Klooster, W.S., Herms, D.A., Knight, K.S., Herms, C.P., McCullough, D.G., Smith, A. Gandhi, K.J.K., Cardina, J., 2014. Ash (Fraxinus spp.) mortality, regeneration, and seed bank dynamics in mixed hardwood forests following invasion by emerald ash borer (Agrilus planipennis). Biol. Invas. 16, 859-873. DOI 10.1007/s10530-013-0543-7

Koch J.L., Carey, D.W., Mason, M.E., Poland, T.M., Knight, K.S., 2015. Intraspecific variation in Fraxinus pennsylvanica responses to emerald ash borer (Agrilus planipennis). New Forests 46, 995-1011. DOI 10.1007/s11056-015-9494-4

Kula, R.R., Knight, K.S., Rebbeck, J., Bauer, L.S., Cappaert, D.L., Gandhi, K.J.K., Slesak, R.A., 2010. Leluthia astigma (Ashmead) (Hymenoptera: Braconidae: Doryctinae) as a parasitoid of Agrilus planipennis Fairmaire (Coleoptera: Buprestidae: Agrilinae), with an assessment of 
host associations for Nearctic species of Leluthia Cameron. Proc. Entomol. Soc. Wash. 112, 246-257. DOI: 10.4289/0013-8797-112.2.246

Larson, K.M., Duan J.J., 2016. Differences in the reproductive biology and diapause of two

600 congeneric species of egg parasitoids (Hymenoptera: Encyrtidae) from northeast Asia:

601 Implications for biological control of the invasive emerald ash borer (Coleoptera: Buprestidae). Biol. Contr. 103, 39-45. http://dx.doi.org/10.1016/j.biocontrol.2016.08.001 603 604 Liebhold, A.M., Macdonald, W.L., Bergdahl, D., Maestro, V.C., 1995. Invasion by exotic forest pests: a threat to forest ecosystems. For. Sci. 41, 1-49.

605

606

607

608

609

610

611

612

613

614

615

616

617

618

619
Lindell, C.A., McCullough, D.G., Cappaert, D., Apostolou, N.M., Roth, M.B., 2008. Factors influencing woodpecker predation on emerald ash borer. Am. Midwest. Nat. 159, 434444.

Liu, H.P., Bauer, L.S., Gao, R.T., Zhao, T.H., Petrice, T.R., and Haack, R.A., 2003. Exploratory survey for the emerald ash borer, Agrilus planipennis (Coleoptera: Buprestidae), and its natural enemies in China. Great Lakes Entomol. 36, 191-204.

Liu, H.P., Bauer, L.S., Miller, D.L., Zhao, T.H., Gao, R.T., Song, Luan, L.Q., Jin, R., Gao, C., 2007. Seasonal abundance of Agrilus planipennis (Coleoptera: Buprestidae) and its natural enemies Oobius agrili (Hymenoptera: Encyrtidae) and Tetrastichus planipennisi (Hymenoptera: Eulophidae) in China. Biol. Contr. 42, 61-71. doi:10.1016/j.biocontrol.2007.03.011

Lockwood, J.L., Hoopes, M.F., Marchetti, M.P., 2007. Invasion Ecology, Malden, MA: Blackwell.

Mapbiocontrol, 2017, www.mapbiocontrol.org. Accessed on March 17, 2016.

MacQuarrie, C.J.K., Scharbach, R., 2015. Influence of mortality factors and host resistance on 
the population dynamics of emerald ash borer (Coleoptera: Buprestidae) in urban forests. Environ. Entomol. 44, 160-173. http://dx.doi.org/10.1093/ee/nvu011

McCullough, D.G., Siegert, N.W., 2007. Estimating potential emerald ash borer (Coleoptera: Buprestidae) populations using ash inventory data. J. Econ. Entomol. 100, 1577-1586.

Marsh, P.M., Strazanac, J.S, Laurusonis, S.Y., 2009 Description of a new species of Atanycolus (Hymenoptera: Braconidae) from Michigan reared from the emerald ash borer. Great Lakes Entomologist 42, 8-15.

Mercader, R.J., Siegert, N.W., Liebhold, A.M., McCullough, D.G., 2011. Influence of foraging behavior and host spatial distribution on the localized spread of the emerald ash borer, Agrilus planipennis. Popul. Ecol. 53, 271-385. doi:10.1007/s10144-010-0233-6

Mitchell, C.E., Power, A.G., 2003. Release of invasive plants from fungal and viral pathogens. Nature 421, 625-627. DOI: 10.1038/nature01317

Murphy, S.M., Lill, J.T., Bowers, M.D., Singer, M.S., 2014. Enemy-free space for parasitoids. Environ. Entomol. 43, 1465-1474. http://dx.doi.org/10.1603/EN13201

Murphy T.C., 2017. Factors influencing impact of biological control agents of the amerald ash borer. M.S. Thesis, University of Massachusetts, Amherst, Massachusetts, 52 pp.

Nisbet, D., Kreutzweiser, D., Sibley, P., Scarr, T., 2015. Ecological risks posed by emerald ash borer to riparian forest habitats: A review and problem formulation with management implications. Forest Ecol. Manag. 358, 165-173. http://dx.doi.org/10.1016/j.foreco.2015.08.030

Parisio, M.S., Gould, J.R., Vandenberg, J.D., Bauer, L.S., Fierke M.K., 2017. Evaluation of recovery and monitoring methods for parasitoids released against emerald ash borer. Biol. Contr. 106, 45-53. http://dx.doi.org/10.1016/j.biocontrol.2016.12.009 
Poland, T.M., McCullough, D.G., 2006. Emerald ash borer: invasion of the urban forest and the threat to North America's ash resource. J. Forestry 104, 118-124.

Rebek, E.J., Herms, D.A., Smitley, D.R., 2008. Interspecific variation in resistance to emerald ash borer (Coleoptera: Buprestidae) among North American and Asian ash (Fraxinus spp.). Environ. Entomol. 37, 242-46.

Roscoe, L.E., Lyons, D.B., Smith, S.M., 2016. Observations on the life-history traits of the North American parasitoid Phasgonophora sulcata Westwood (Hymenoptera: Chalcididae) attacking Agrilus planipennis (Coleoptera: Buprestidae) in Ontario, Canada. Can. Entomol. 148, 294-306. doi:10.4039/tce.2015.72

Rutledge, C.E., Keena, M.A., 2012. Mating frequency and fecundity in the emerald ash borer, Agrilus planipennis (Coleoptera: Buprestidae). Ann. Entomol. Soc. Amer. 105, 66-72. DOI: http://dx.doi.org/10.1603/AN11037

SAS Institute Inc. (2014) JMP ${ }^{\circledR}$ Pro 11.0.2 Statistical Software. SAS Institute Inc, SAS Campus Drive, Cary, NC 27513, USA.

Siegert, N.W., McCullough, D.G., Williams, D.W., Fraser, I., Poland, T.M., Pierce, S.J., a2010. Dispersal of Agrilus planipennis (Coleoptera: Buprestidae) from discrete epicenters in two outlier sites. Environ. Entomol. 39, 253-265. DOI: 10.1603/EN09029

Slesak, R.A., Lenhart, C.F., Brooks, K.N., D’Amato, A.W., Palik, B.J., 2014. Water table response to harvesting and simulated emerald ash borer mortality in black ash wetlands in Minnesota, USA. Can. J. Forest Res. 44, 961-968. dx.doi.org/10.1139/cjfr-2014-0111

Smith, A., 2006. Effects of community structure on forest susceptibility and response to the emerald ash borer invasion of the Huron River watershed in southeast Michigan. M.S. thesis, Ohio State University, Columbus, Ohio 122 pp. 
Stephens, J.P., Berven, K.A., Tiegs, S.D., 2013. Anthropogenic changes to leaf litter input affect the fitness of a larval amphibian. Freshwater Biol. 58, 1631-1646. doi: 10.1016/j.aquatox.2013.05.012

Ulyshen, M.D., Duan, J.J., Bauer, L.S., Fraser, I., 2010. Suitability and accessibility of immature Agrilus planipennis (Coleoptera: Buprestidae) stages to Tetrastichus planipennisi (Hymenoptera: Eulophidae). J. Econ. Entomol. 103, 1080-1085. DOI: 10.1603/EC10024

Ulyshen, M.D., Barrington, W.T., Hoebeke, E.R., Herms, D.A., 2012. Vertically stratified ashlimb beetle fauna in northern Ohio. Psyche (Cambridge), 2012, article 215891. http://dx.doi.org/10.1155/2012/215891.

Ulyshen, M.D., Klooster, W.S., Barrington, W.T., Herms, D.A., 2011. Impacts of emerald ash borer-induced tree mortality on leaf litter arthropods and exotic earthworms. Pedobiologia 54, 261-265. doi:10.1016/j.pedobi.2011.05.001

USDA-APHIS/ARS/FS (USDA-Animal Plant Health Inspection Service/Agricultural Research Service/Forest Service), 2016. Emerald Ash Borer Biological Control Release and Recovery Guidelines. USDA APHIS-FS-ARS, Riverdale, Maryland. https://www.aphis.usda.gov/plant_health/plant_pest_info/emerald_ash_b/downloads/EA B-FieldRelease-Guidelines.pdf [Accessed 30 December 2016]

van den Bosch, R., Messenger, P.S., Gutierrez, A.P., 1982. An Introduction to Biological Control. Plenum Press, New York.

Van Driesche, R.G. Taub, G., 1983. Field evaluation of the impact of parasites on Phyllonorycter leafminers on apple in Massachusetts, U.S.A. Prot. Ecol. 5, 303-317. 
Van Driesche, R.G., Reardon, R.C., 2014. The Use of Classical Biocontrol to Preserve Forests in North America. United States Department of Agriculture, Forest Service, Forest Health Technology Enterprise Team, FHTET-2013-2, Morgantown, West Virginia.

Van Driesche, R.G., Carruthers, R.I., Center, T., Hoddle, M.S., Hough-Goldstein, J., Morin, L., Smith, L., Wagner, D.L., et al., 2010. Classical biological control for the protection of natural ecosystems. Biol. Control 45, S22-S33. doi:10.1016/j.biocontrol.2010.03.003

Wagner, D.L., Todd, K.J., 2016. New ecological assessment for the emerald ash borer: a cautionary tale about unvetted host-plant literature. Am. Entomol. 65, 26-35. http://dx.doi.org/10.1093/ae/tmw005

Wu, H., Li, M., Yang, Z., Wang, X., Wang, H., Bai, L., 2007. Cold hardiness of Agrilus planipennis and its two parasitoids, Spathius agrili and Tetrastichus planipennisi. Chinese J. Biol.Contr. 23, 119-122.

Yang, Z.Q., Strazanac, J.S., Marsh, P.M., Van Achterberg, C., Choi, W.Y., 2005. First recorded parasitoid from China of Agrilus planipennis: a new species of Spathius (Hymenoptera: Braconidae: Doryctinae). Ann. Entomol. Soc. Am. 98, 636-642. 
Table 1. Life table for emerald ash borer population infesting ash saplings observed in 2015 at pooled at this site from the parasitoid release and non-release control plots for life table construction.

\begin{tabular}{|c|c|c|c|c|c|c|c|c|}
\hline Life stage $^{a}$ & $1_{\mathrm{x}}$ & $\mathrm{m}_{\mathrm{x}}$ & $\mathrm{d}_{\mathrm{x}}$ & $\mathrm{d}_{\mathrm{i}}$ & Mortality Factor & $\mathrm{q}_{\mathrm{x}}=\mathrm{dx} / \mathrm{lx}$ & $\mathrm{q}_{\mathrm{i}}=\mathrm{d}_{\mathrm{i}} / \mathrm{l}_{\mathrm{x}}$ & $\mathrm{q}=\mathrm{d}_{\mathrm{x}} / \mathrm{I}_{0}$ \\
\hline$(\mathrm{Egg})$ & (26) & - & (8) & & (Oobius agrili $30 \%$ ) & & & $(0.300)$ \\
\hline \multirow[t]{3}{*}{ L1-L2 } & 18 & 10 & 0 & 0 & Parasitism (total) & 0.00 & 0.00 & 0.00 \\
\hline & - & - & 0 & 0 & Undetermined & 0 & 0 & 0 \\
\hline & - & - & - & 0 & Avian predation & - & 0 & - \\
\hline \multirow[t]{5}{*}{ L3-L4 } & 8 & 4 & 4 & 4 & Parasitism (total) & 0.5 & 0 & 0.1538 \\
\hline & - & - & - & 4 & T. planipennissi & - & 0.5 & - \\
\hline & - & - & - & 0 & Atanycolus spp. & - & - & - \\
\hline & - & - & - & 0 & Undetermined & - & - & - \\
\hline & - & - & - & 0 & Avian predation & - & - & - \\
\hline (Adults) & (4) & (4) & - & $(0.2)$ & (Fungus disease - 5\%) & - & - & $(0.050)$ \\
\hline (Females) & (2) & - & - & - & (Female: male $=1: 1)$ & - & - & - \\
\hline (F1 eggs) & $(60)$ & - & - & - & (30 fertilized eggs/Female) & - & - & - \\
\hline $\mathrm{R}_{0}$ & 2.2 & - & - & - & - & - & - & - \\
\hline$\left(\mathrm{R}_{0-\mathrm{TP}}\right)$ & (4.4) & & & & (T. planipennisi is removed) & & & \\
\hline
\end{tabular}

\footnotetext{
${ }^{\mathrm{a}}$ Parameters for life stages in parenthesis were calculated based on separate estimates from earlier studies (Abell et al. 2014). Live $\left(m_{x}\right)$ small larvae (L1-L2s) were excluded from parameter estimates because of the observed twoyear generation (see Duan et al. 2014). Column headings represent: $1_{\mathrm{x}}=$ number of live EAB entering each stage; $\mathrm{m}_{\mathrm{x}}$ $=$ number of live EAB observed at sampling time; $d_{x}=$ number of dead EAB observed in each stage; $q_{x}=$ apparent (stage-specific) mortality rate $\left(\mathrm{d}_{\mathrm{x}} / \mathrm{l}_{\mathrm{x}},\right) ; \mathrm{d}_{\mathrm{i}}=$ number of EAB dying by a specific mortality factor; $\mathrm{q}_{\mathrm{i}}=$ apparent mortality rate caused by a specific factor $\left(\mathrm{d}_{\mathrm{i}} / \mathrm{l}_{\mathrm{x}}\right) ; \mathrm{q}=$ real mortality $\left(\mathrm{d}_{\mathrm{x}}\right.$ or $\left.\mathrm{d}_{\mathrm{i}} / \mathrm{l}_{0}\right), \mathrm{R}_{0}=$ net reproductive rate, calculated as the ratio of $l_{0}$ (number of eggs estimated to start the life table) divided by $l_{F 1}$ (the number of eggs produced by surviving adults). $\mathrm{R}_{0 \text {-TP }}=$ net reproductive rate when the 4 parasitized host larvae by $T$. planipennisi were allowed to survive but subject to the same rates of mortality caused by other biotic factors.
} 
719 Fig. 1. Percentage of ash saplings with current infestations of emerald ash borer larvae (A) and 720 emerald ash borer densities (all instars including emerged adults) per unit area $\left(\mathrm{m}^{2}\right)$ of sampled 721 ash phloem (B) in both biocontrol-release and non-release control plots in southern Michigan 722 during the three-year study (2013-2015).

723 Fig. 2. Percent parasitism of late-instar emerald ash borer larvae by the introduced biocontrol 724 agent Tetrastichus planipennisi (A) and the North American native parasitoid Atanycolus spp. 725 (B) in both the biocontrol-release and non-release control plots in southern Michigan during the 726 three-year study (2013-2015).

727 Fig. 3. Percent predation of emerald ash borer larvae and pupae by woodpeckers and other bark728 foraging birds (A) and percentage mortality of emerald ash borer larvae by undetermined biotic 729 factors such as putative host tree resistance, disease and/or intraspecific competition (B) in both 730 biocontrol-release and non-release control plots in southern Michigan during the three-year study 731 (2013-2015).

732 Fig. 4. Net population growth rates $\left(\mathrm{R}_{0}\right)$ of emerald ash borer populations infesting ash saplings 733 across different study sites (pooled from both parasitoid release and non-release control plots for 734 each site) in southern Michigan in each of the three years of the study (2013-2015).

735 Fig. 5. Number of ash trees per $100 \mathrm{~m}^{2}$ with different crown-condition (CC) classifications at the 736 six study sites in southern Michigan observed in summer 2015. All saplings and trees were 737 classified based on CC scores of 1 to 5 at $10 \%$ increments. Healthy Ash Trees are CC range $1-$ 7382 (A), Declining Ash Trees are CC range 2.5 - 3.5 (B), and dead/dying Ash Trees are CC range $7394-5(\mathrm{C})$. Study sites labeled on the $\mathrm{X}$-axis are: $\mathrm{BF}=$ Burchfield Park, $\mathrm{CP}=$ Central Park-Nancy 
740 Moore Parks (Meridian Township Park), LP = Legg Park-Harris Nature Center (Meridian

741 Township Park), GSW = Gratiot Saginaw State Game Area, MRE = Maple River State Game

742 Area, and RL $=$ Rose Lake State Wildlife Area.

743 Fig. 6. Distribution (relative percentage) of different crown-condition (CC) classifications in

744 relation to size (DBH) categories observed in the six study sites located in southern Michigan in

745 summer 2015. Green bars represent healthy trees with CC 1-2, yellow bars declining trees with

746 CC 2.5-3.5, and black bars dead/dying trees with CC 4-5. 
$747 \quad$ Fig. 1
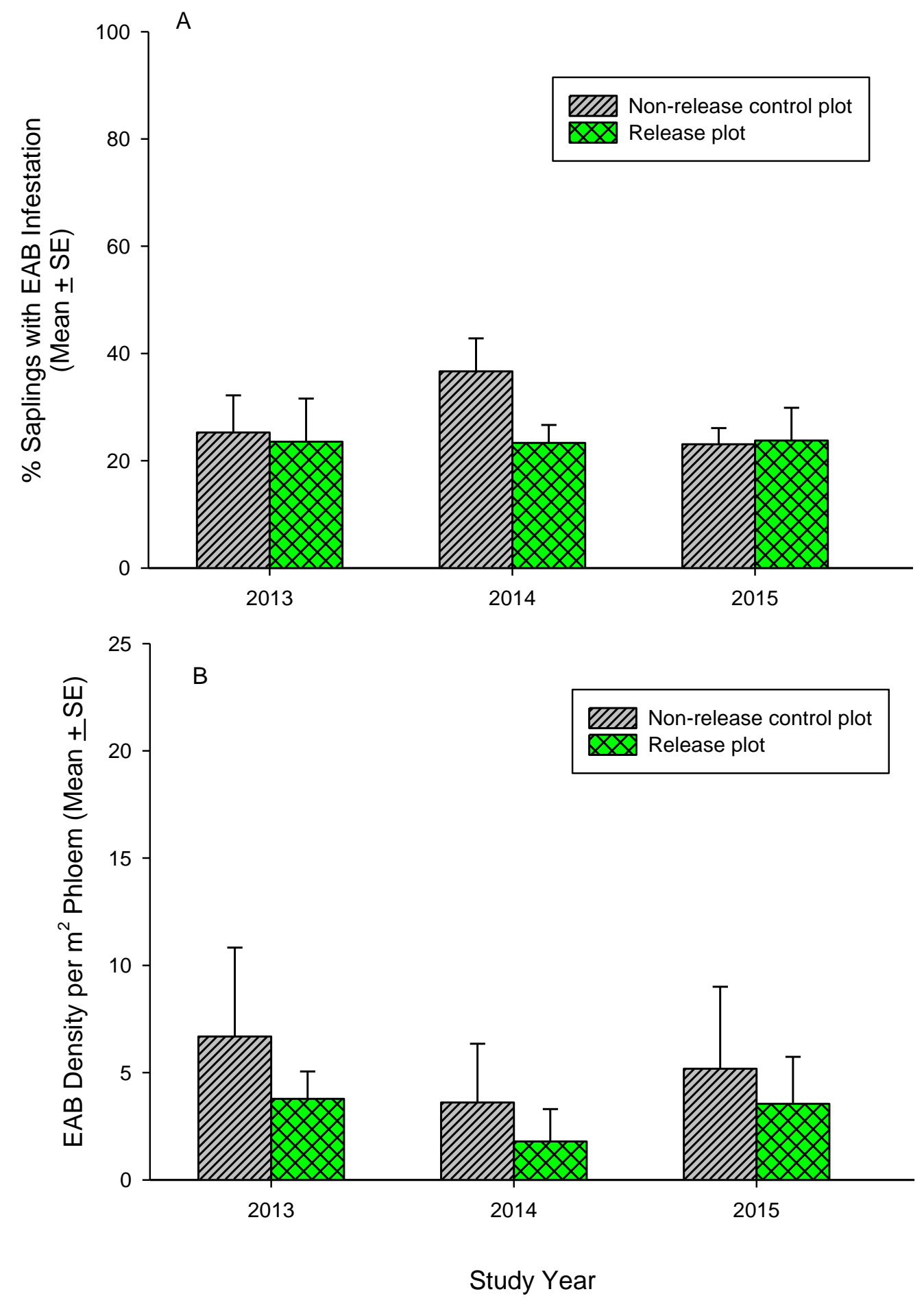
749 Fig. 2
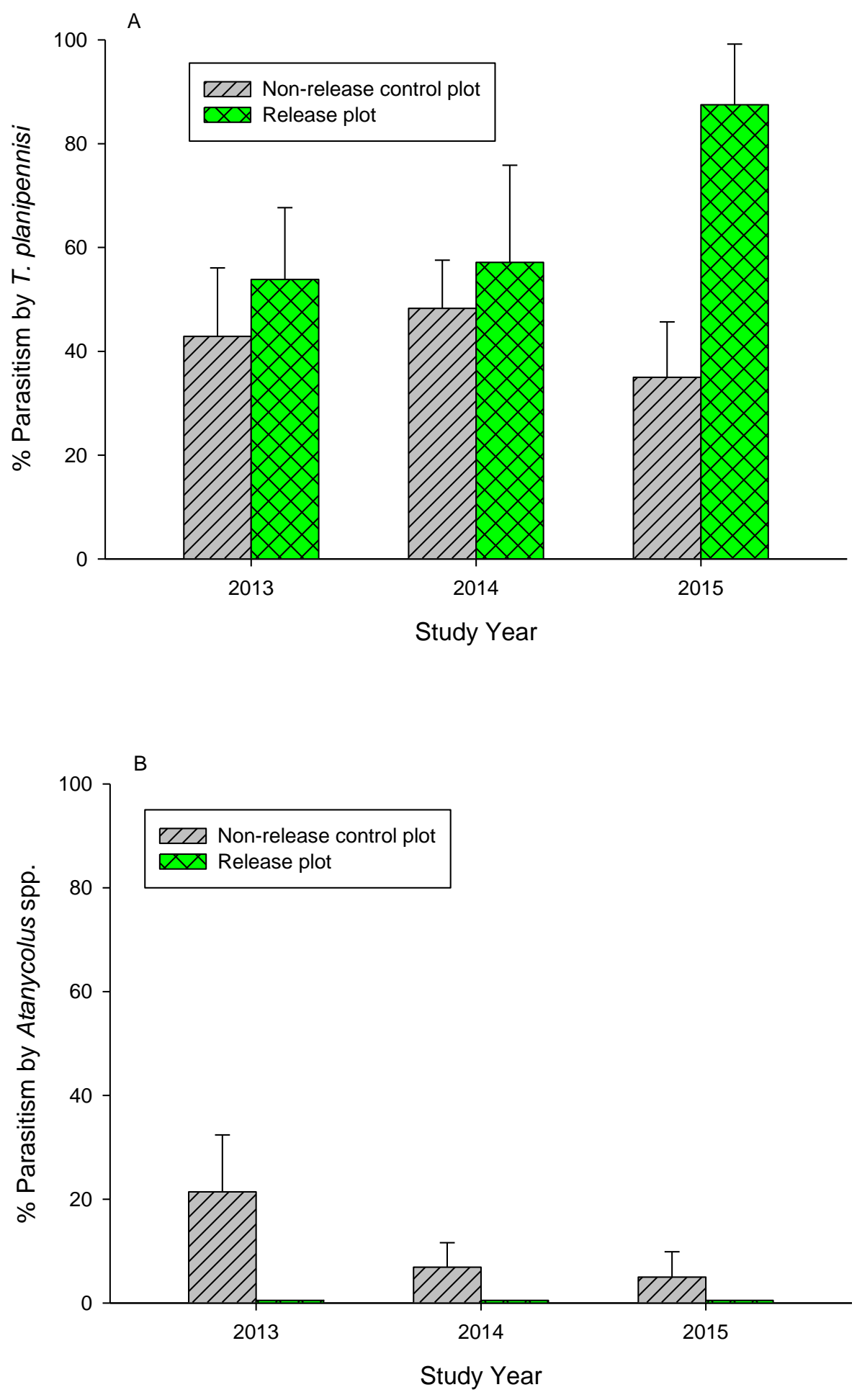
751 Fig. 3
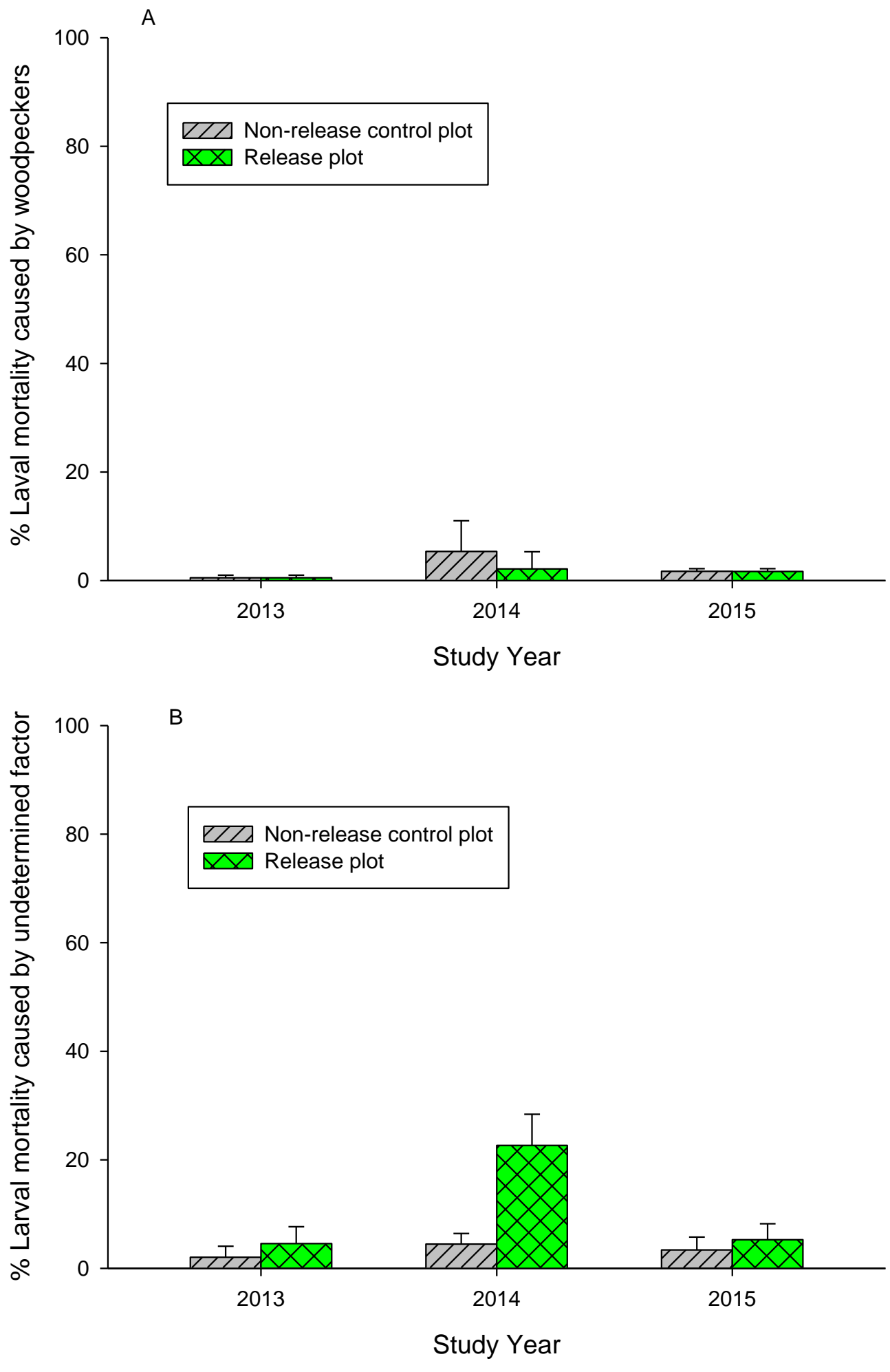
753 Fig. 4

754

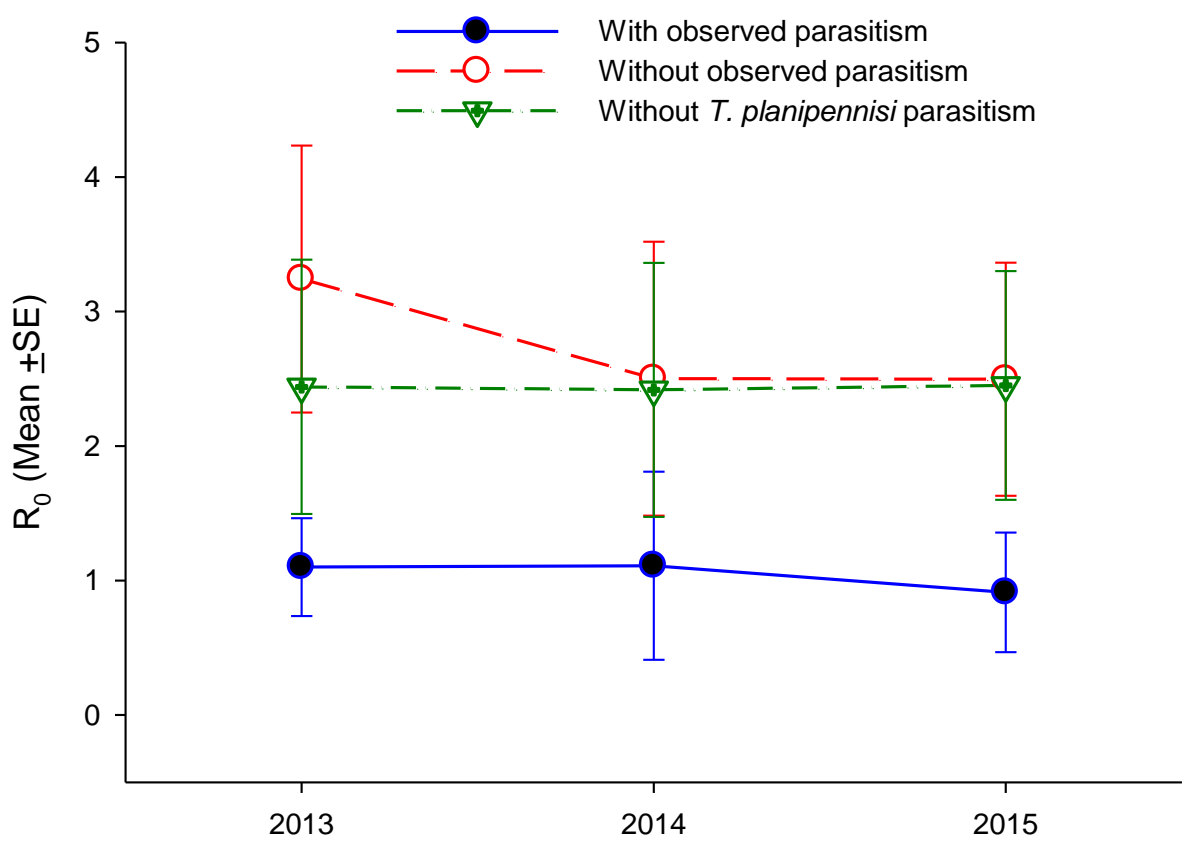

755

Study Year

756 
Fig. 5
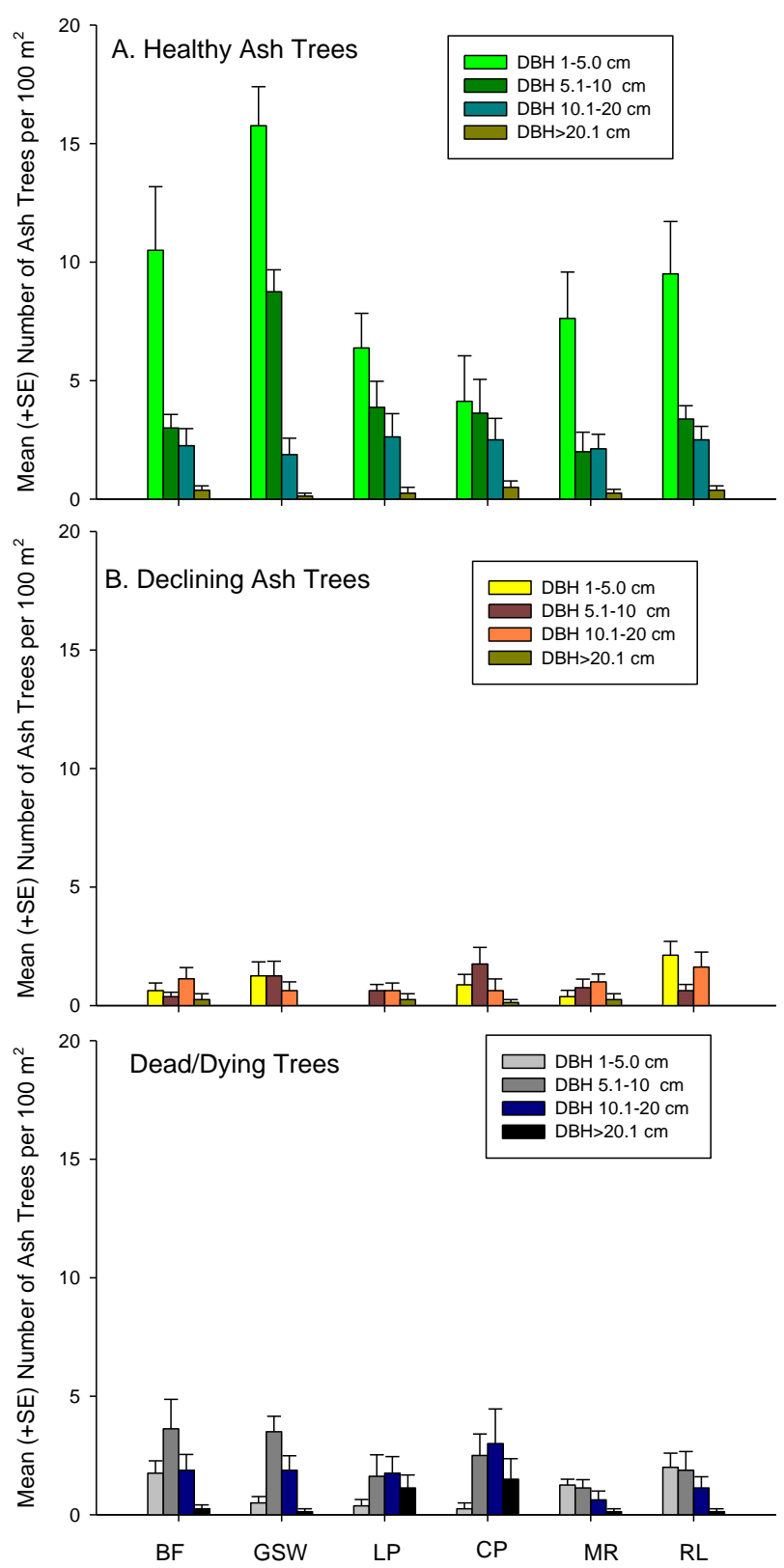

Study Sites in Michigan 
$759 \quad$ Fig. 6

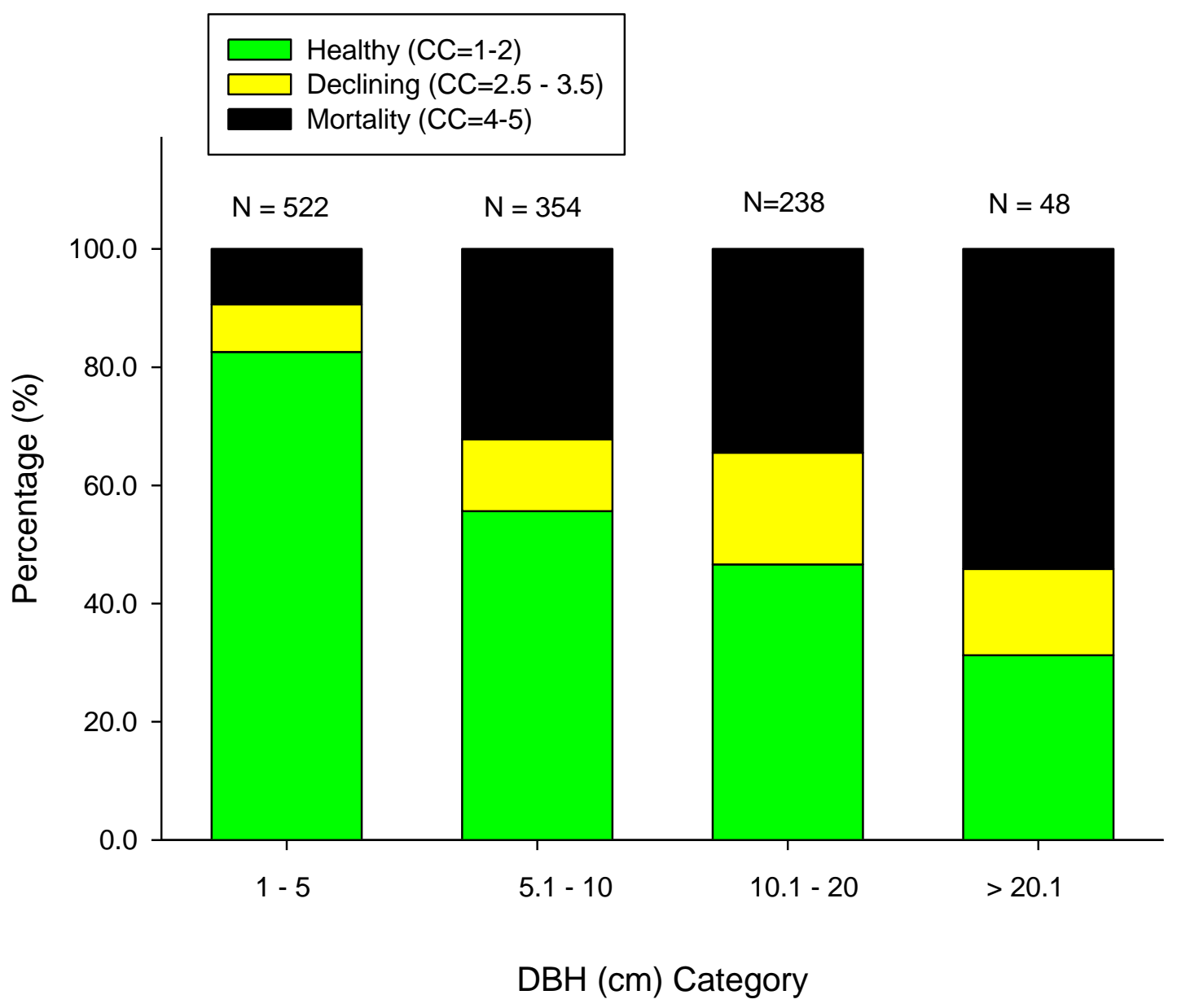

